\title{
FISIOLOGIA DE VARIEDADES DE PEREIRA SOB DIFERENTES SISTEMAS E LÂMINAS DE IRRIGAÇÃO NO SEMIÁRIDO BRASILEIRO
}

\section{PHYSIOLOGY OF VARIETIES OF PEREIRA UNDER DIFFERENT SYSTEMS AND IRRIGATION LEAVES IN THE BRAZILIAN SEMIARIATE}

\author{
Welson Lima Simões ${ }^{1}$; Victor Hugo Freitas ${ }^{2}$; Paulo Roberto Coelho ${ }^{3}$; Jair Andrade Lima4; \\ Marcelo Calgaro 5
}

DOI: https://doi.org/10.31692/978-65-991061-7-0.133-142

\begin{abstract}
RESUMO
Trabalhos têm demonstrado a viabilidade socioeconômica do cultivo da pereira em perímetros irrigados na região semiárida brasileira, sendo uma nova alternativa sustentável para os produtores da região. Em condições de semiaridez, diversos fatores, como a disponibilidade hídrica do solo, o tipo de sistema de irrigação, bem como a variedade empregada no sistema de produção agrícola, pode afetar os processos fisiológicos das plantas. Objetivou-se com o estudo avaliar o efeito fisiológico de duas variedades de pereira com diferentes sistemas e lâminas de irrigação no Vale do Submédio São Francisco. O delineamento experimental foi em blocos casualizados com esquema fatorial $2 \times 2 \times 4$, sendo dois sistemas de irrigação (gotejamento e microaspersão), duas variedades (Triunfo e Packham's triumph) e quatro lâminas d'água (60; 80; 100; e 120\% da Evapotranspiração da cultura - ETc), com quatro repetições. As lâminas de irrigação causaram alteração nas trocas gasosas, em que as lâminas estimadas de $97,86 \%, 100,88 \%, 97,63 \%$ da ETc proporcionaram as maiores médias para condutância estomática $\left(0,41 \mathrm{~mol} \mathrm{~m} \mathrm{~m}^{-2} \mathrm{~s}^{-1}\right)$, transpiração $\left(8,77 \mathrm{mmol} \mathrm{H}_{2} \mathrm{O} \mathrm{m}^{-2} \mathrm{~s}^{-1}\right)$, e fotossíntese líquida $\left(27,22 \mu \mathrm{mol} \mathrm{CO}_{2} \mathrm{~m}^{-2} \mathrm{~s}^{-1}\right)$, respectivamente, enquanto que para $\mathrm{o}$ parâmetro temperatura foliar o valor mínimo estimado foi de $31,26^{\circ} \mathrm{C}$ com a lâmina de $99,31 \%$ da ETc. Não se observou interação entre as variedades e os sistemas de irrigação sob as características fisiológicas das pereiras.
\end{abstract}

Palavras-Chave: Microirrigação, manejo, trocas gasosas, Pyrus communis.

\begin{abstract}
Studies have demonstrated the socioeconomic viability of pear cultivation in irrigated perimeters in the Brazilian semiarid region, being a new sustainable alternative for producers in the region. To do so, in semiarid conditions, plants have mechanisms that can affect their physiological processes, such as soil water availability, type of irrigation system, as well as species and variety used in agricultural production systems. Thus, the objective of this study was to evaluate the physiological effect of two varieties of pear tree on different systems and irrigation leaves in the Submédio São Francisco. The experimental design was a randomized complete block design with $2 \times 2 \times 4$ factorial design, two irrigation systems (drip and micro sprinkler), two varieties (Triunfo and Packham's triumph) and four water leaves (L1 - 60\%, L2 - 80\%, L3 - 100\% and L4 - 120\% of crop Evapotranspiration - ETc), with four replicates. The irrigation leaves caused changes in the gas exchange, in which the leaves estimated in $97.86 \%, 100.88 \%, 97.63 \%$ of ETc provided the highest averages for the characteristics: stomatal conductance $\left(0.41 \mathrm{~mol} \mathrm{~m}^{-2}\right)$ and transpiration $\left(8.77 \mathrm{mmol} \mathrm{H}_{2} \mathrm{O} \mathrm{m} \mathrm{m}^{-2}\right)$, and liquid

\footnotetext{
${ }^{1}$ Doutor em engenharia agrícola, EMBRAPA Semiárido, welson.simoes@embrapa.br

${ }^{2}$ Mestre em engenharia agrícola, Universidade Federal do Vale do São Francisco, victorhfg@ hotmail.com

${ }^{3}$ Doutor em agronomia, EMBRAPA Semiárido, paulo.roberto@embrapa.br

${ }^{4}$ Titulação, Instituição, e-mail

${ }^{5}$ Doutor em engenharia agrícola, EMBRAPA Semiárido, marcelo.calgaro@embrapa.br
} 
photosynthesis $\left(27.22 \mu \mathrm{mol} \mathrm{CO}_{2} \mathrm{~m}^{-2} \mathrm{~s}^{-1}\right)$, respectively, whereas for the leaf temperature parameter the estimated minimum value for this characteristic was $31.26{ }^{\circ} \mathrm{C}$ was on the $99.31 \%$ leave of ETc. There was no interaction between varieties and irrigation systems under the physiological characteristics of pear trees.

Keywords: Microirrigation, handling, gas exchange, Pyrus communis.

\section{INTRODUÇÃO}

A pereira (Pyrus communis) é uma espécie oriunda de zonas temperadas da Europa e da Ásia. No Brasil, essa cultura é cultivada nas regiões Sul e Sudeste devido as condições climáticas, como médias superiores a 810 horas de frio abaixo de $7,2^{\circ} \mathrm{C}$ (WREGE, et al, 2016).

Durante muito tempo as características edafoclimáticas limitavam o cultivo da pereira para as regiões mais frias do país. No entanto, a partir de programas de melhoramento genético realizados no país, foi possível obter cultivares que suportam baixo requerimento de frio (BETTIOL NETO et al., 2014).

Nesse contexto, estudos têm demonstrado a viabilidade socioeconômica do cultivo da pereira no Vale do Submédio São Francisco, utilizando cultivares que requerem poucas horas de frio para superar essa fase de dormência (LOPES et al., 2013). Nessa região a exploração de algumas plantas cultivadas só é possível em função da técnica da irrigação devido, principalmente, a fatores climáticos como altas temperaturas, baixa umidade relativa do ar e má distribuição de chuvas (LOPES et al., 2017).

Nessas condições, se a compensação de água não for suficiente, as plantas reduzem as suas taxas fotossintéticas, comprometendo a produção de fotoassimilados e consequentemente a sua produtividade (TAIZ \& ZEIGER, 2017; ZHAO et al., 2015). Além disso, os parâmetros fisiológicos de uma cultura podem sofrer influência da variedade empregada, principalmente, pela sua tolerância ao déficit de água.

As características fisiológicas de fruteiras, como a mangueira, também têm demonstrado alterações com relação ao tipo e ao arranjo do sistema de irrigação utilizados para seu cultivo na região do Submédio São Francisco (SIMÕES et al., 2018). Diante do exposto, o objetivo desse estudo foi avaliar o efeito dos sistemas e das lâminas de irrigação sobre as características fisiológicas de duas cultivares de pereira no Submédio São Francisco.

\section{FUNDAMENTAÇÃO TEÓRICA}

A água é um recurso indispensável para a produção agrícola, por participar ativamente no funcionamento das células e tecidos vegetais (SILVA et al., 2016). Esse líquido está envolvido nos processos fisiológicos da planta, dos quais destacam-se a fotossíntese e a 
hidrólise do amido em açúcar (TAIZ \& ZEIGER, 2017).

Dessa forma, a diminuição no conteúdo de água na célula pode ocasionar mudanças estruturais e, em último caso, a morte da célula. Também, o déficit hídrico resulta em diminuições nas taxas de crescimento e produtividade, em virtude da redução do potencial hídrico das folhas, fechamento estomático e consequente diminuição das trocas gasosas (RODRIGUES et al., 2018).

Esses fatores inibem diversos processos bioquímicos e fisiológicos, como a fotossíntese, respiração, divisão celular, síntese de proteínas, acúmulo de solutos e absorção de íons. Outrossim, a deficiência de água diminui a absorção de nutrientes e água pela raiz, provocando baixo crescimento radicular e, consequentemente, diminuição no transporte de solutos para a parte aérea (NEMESKÉRI et al. 2015; TAIZ \& ZEIGER, 2017).

Em virtude disso, a absorção efetiva de água pelas raízes depende do contato entre a superfície radicular e o solo, das condições físicas do movimento de água para a planta, bem como da relação entre estes elementos e a necessidade hídrica da planta nos seus diferentes estádios fenológicos (ALBUQUERQUE \& DURÃES, 2008).

De uma maneira geral, a transpiração das espécies vegetais é determinada pela ação do clima, mecanismos fisiológicos relacionados com respostas estomáticas a fatores ambientais, índice de área foliar e disponibilidade de água no solo (TAIZ \& ZEIGER, 2017). Assim, o déficit de água no solo provoca a queda do rendimento da cultura, principalmente pelo fechamento dos estômatos que diminui a absorção de $\mathrm{CO}_{2}$, reduzindo a fotossíntese (PADILHA et al., 2016).

Em condições de períodos secos a ação dos fatores afeta a difusão de $\mathrm{CO}_{2}$ por conta da redução da condutância estomática e mesofílica. A condutância estomática é um evento fisiológico que as plantas possuem para o controle da transpiração (FLEXAS et al., 2004; PADILHA et al., 2016). Os estômatos se fecham em consequência da diminuição da turgescência das células, devido à alta deficiência de pressão de vapor na atmosfera ou a sinais químicos gerados pelas raízes (CHAVES et al., 2009).

As plantas, de um modo geral, apresentam mecanismos de defesa que minimizam o seu desenvolvimento em condições adversas, como: redução da superfície foliar e diminuição do número de folhas, acúmulo de solutos, aceleração da senescência e abscisão das folhas e o aumento da relação raiz-parte aérea (BIANCHI et al., 2007; RODRIGUES et al., 2018; TAIZ \& ZEIGER, 2017). Dessa forma, essas estratégias de defesa impostas pela planta limitam o consumo de água, evitando-se o gasto de energia durante o seu metabolismo (NEMESKÉRI et al. 2015). 
O manejo da irrigação é muitas vezes comprometido também por aplicar-se lâminas de irrigação em excesso, ocasionando em uma série de fatores que inibem o crescimento da planta (SARAIVA et al., 2013). Dentre essas causas podem-se citar, a baixa disponibilidade de oxigênio no solo limitando a atividade microbiana e o crescimento radicular, além da lixiviação de nutrientes em virtude da alta velocidade de infiltração em solos arenosos (OLIVEIRA \& GUALTIERI, 2017; OLIVEIRA et al., 2008).

Também, o tipo de sistema de irrigação pode influenciar nos aspectos bioquímicos e fisiológicos da planta. Em sistemas por gotejamento a aplicação de água é mais próxima ao sistema radicular, e nesse cenário a planta gasta menos energia em busca de água e nutrientes, direcionando esse esforço para a sua produção (COELHO et al, 2001; TAIZ \& ZEIGER, 2017).

Por outro lado, na microaspersão a superfície molhada é maior, quando comparado com o gotejamento, o que favorece para o aumento do volume de raízes no perfil do solo, ocasionando em uma maior zona de absorção de água e nutrientes, diminuindo o estresse hídrico (FRIZZONE et al., 2012).

Ademais, esse tipo de sistema pode proporcionar um microclima agradável para o desenvolvimento das plantas, tendo em vista que nessa situação a umidade relativa do ar pode se tornar alta devido às partículas de água em suspensão, diminuindo a temperatura do ambiente, influenciando nos processos de fotossíntese e transpiração, refletindo na produção de fotoassimilados (TAIZ \& ZEIGER, 2017).

Além da adoção de técnicas inovadoras na irrigação como os sistemas de aplicação localizada, o uso de genótipos resistentes ao déficit hídrico também é outra alternativa para o cultivo promissor da pereira em zonas áridas e semiáridas e o seu desempenho físiológico depende da espécie e do cultivar empregado nos sistemas de produção (ZARAFSHAR et al., 2014).

Assim, o manejo eficiente da irrigação busca atender as necessidades hídricas da cultura, proporcionando água no tempo certo e na quantidade correta, evitando o desperdício

\section{METODOLOGIA}

O experimento foi conduzido na fazenda Frutos do Sol, no distrito de irrigação Senador Nilo Coelho - Núcleo 5 (9²1'27.65" de latitude sul e 40³7'56.07" de longitude oeste), localizado no município de Petrolina - PE. O trabalho foi realizado com a pereira (Pyrus communis), com quatro anos de idade e espaçamento de 3,5 x 1,25 m.

O clima da região é o Semiárido, com temperatura média anual de $26,5^{\circ} \mathrm{C}$, classificado 
como BSwh, por Köppen, apresentando os maiores picos entre outubro e dezembro, enquanto julho é o mês mais frio (LOPES et al., 2017). A classificação textural do solo da área é arenosa, conforme observado na tabela 1 .

Tabela 1. Analise física do solo: Densidade do solo (Ds), densidade de partícula (Dp), porosidade total (Pt), teores de areia, silte, argila e classificação textural da área experimental da pereira no Submédio São Francisco.

\begin{tabular}{cccccccc}
\hline $\begin{array}{c}\text { Profundidade } \\
(\mathrm{cm})\end{array}$ & $\begin{array}{c}\text { Ds } \\
\left(\mathrm{g} . \mathrm{cm}^{-3}\right)\end{array}$ & $\begin{array}{c}\mathrm{Dp} \\
\left(\mathrm{g} . \mathrm{cm}^{-3}\right)\end{array}$ & $\begin{array}{c}\text { Pt } \\
(\%)\end{array}$ & $\begin{array}{c}\text { Areia } \\
(\%)\end{array}$ & $\begin{array}{c}\text { Silte } \\
(\%)\end{array}$ & $\begin{array}{c}\text { Argila } \\
(\%)\end{array}$ & $\begin{array}{c}\text { Classe } \\
\text { textural }\end{array}$ \\
\hline $0-20$ & 1,55 & 2,39 & 35,31 & 82,5 & 12,9 & 4,6 & Arenosa \\
$20-40$ & 1,62 & 2,58 & 37,24 & 83,0 & 12,1 & 4,9 & Arenosa \\
$40-60$ & 1,62 & 2,56 & 37 & 80,1 & 15,6 & 4,3 & Arenosa \\
\hline
\end{tabular}

O delineamento experimental foi em blocos ao caso em esquema fatorial $2 \times 2 \times 4$, com três repetições, sendo duas cultivares de pereira (Triunfo e Packham's triumph), dois sistemas de irrigação localizada (gotejamento e microaspersão) e quatro lâminas de irrigação (60; 80; 100 e 120\% da evapotranspiração da cultura - ETc). Cada parcela foi constituída por 10 plantas, sendo úteis as três centrais.

As irrigações foram realizadas diariamente a partir de dados da ETc, sendo os valores da Eto estimado pelo método de Penman-Monteith, conforme descrito por Allen et al. (2006), obtidos por uma estação meteorológica instalada próxima à área experimental e o coeficiente da cultura $(\mathrm{Kc})$ usado, também indicado pelos mesmos autores.

Avaliou-se a fisiologia da planta durante a frutificação com medições pontuais, entre 8 e 10 horas do dia, em folhas totalmente expandidas e completamente formadas. As leituras foram feitas com a utilização do medidor de trocas gasosas (IRGA - Modelo Li 640 Licor). Foram mensuradas a temperatura foliar, taxas de fotossíntese, transpiração e condutância estomática.

Os resultados foram submetidos a análise de variância, estudando a interação entre os fatores: cultivares, sistemas e lâminas de irrigação quando significativa, comparando as médias através do teste de Tukey para os atributos qualitativos e a análise de regressão para os fatores quantitativos ao nível de $5 \%$ de probabilidade.

\section{RESULTADOS E DISCUSSÃO}

De acordo com a análise de variância não houve interação significativa entre as variedades, sistemas e as lâminas de irrigação para os fatores avaliados. No entanto, observou-se efeito apenas das lâminas de irrigação $(\mathrm{p}<0,05)$ para as variáveis fisiológicas: condutância estomática, transpiração, temperatura foliar e fotossíntese.

Para as características condutância estomática (Figura 1A), transpiração (Figura 1B), 
fotossíntese (Figura 1C) e temperatura foliar (Figura 1D) observou-se que as equações ajustadas são polinomiais do segundo grau. Na figura 1A pode-se notar que a lâmina de irrigação estimada em $97,86 \%$ da ETc proporcionou a maior abertura estomática 0,41 mol.m $2 \cdot \mathrm{S}^{-1}$.

Figura 2. Efeito das lâminas de irrigação sobre: A - Condutância estomática (gs); B - Transpiração (E); C Fotossíntese (A); D - Temperatura foliar, na pereira no Submédio São Francisco.
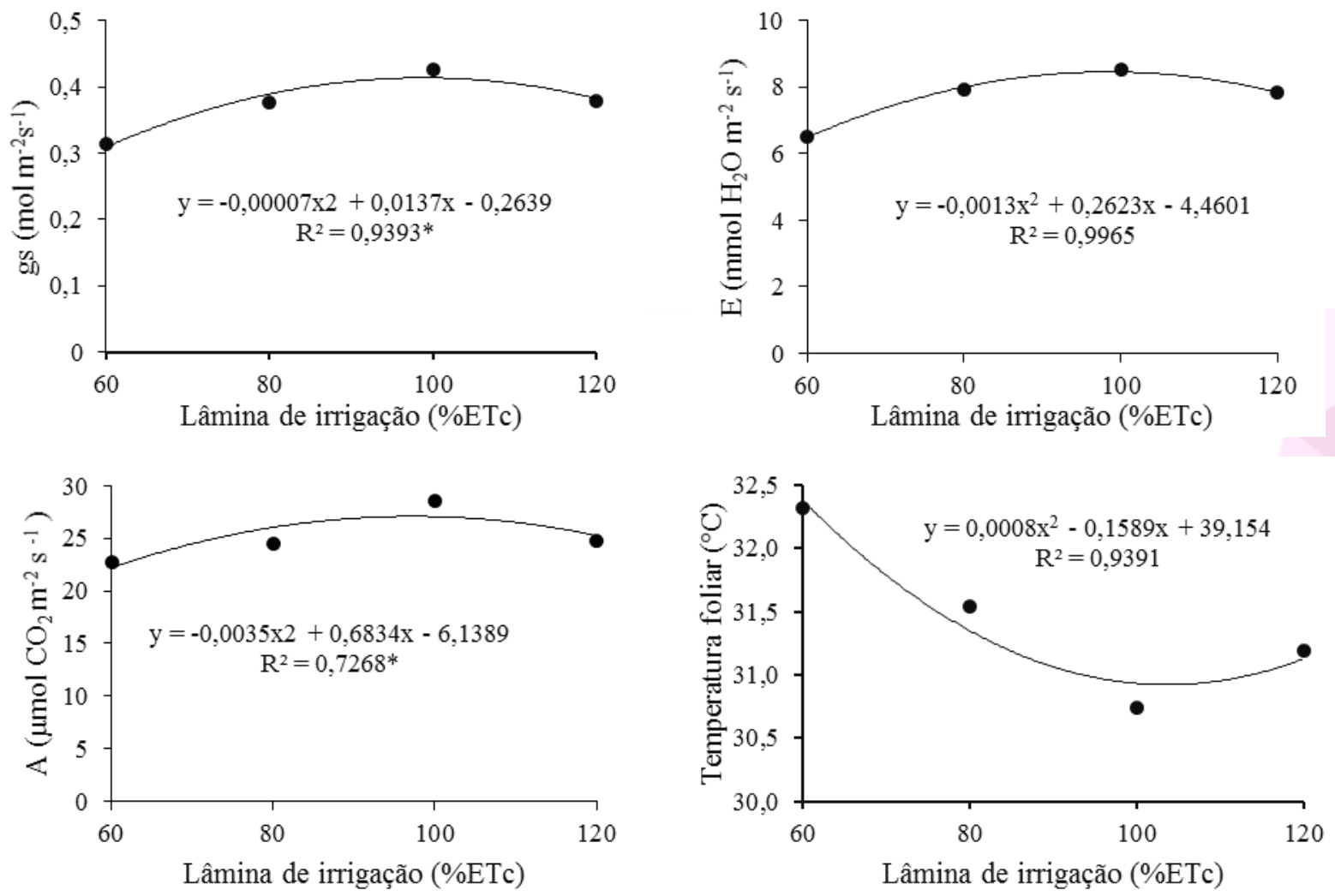

Na figura $1 \mathrm{C}$ observa-se também que o valor máximo alcançado para a fotossíntese liquida correspondeu à 27,22 $\mu \mathrm{mol} \mathrm{CO}_{2} \mathrm{~m}^{-2} \mathrm{~s}^{-1}$ na lâmina de $97,63 \%$ da ETc. Com relação a transpiração (Figura 1B) a lâmina estimada em 100,88\% da ETc propiciou o maior valor para essa característica com uma média de $8,77 \mathrm{mmol} \mathrm{H}_{2} \mathrm{O} \mathrm{m}^{-2} \mathrm{~s}^{-1}$. Já para a temperatura foliar (Figura 1D) o volume de água que proporcionou a menor média $31,26{ }^{\circ} \mathrm{C}$ foi a lamina de $99,31 \%$ da ETc.

A partir dos resultados encontrados pode-se observar que os parâmetros fotossintéticos avaliados se correlacionam entre si, tendo em vista que as plantas quando submetidas a uma boa disponibilidade hídrica obtiveram uma maior abertura estomática proporcionando aumento nas taxas de transpiração e de fotossíntese líquida na cultura da pereira.

Portanto, em condições de boa disponibilidade hídrica, isto é, em condições onde o solo se encontra próximo a capacidade de campo, os vegetais tendem a apresentar altas taxas 
transpirométricas (OLIVEIRA et al., 2017). Dessa forma, a redução hídrica diminui as trocas gasosas na cultura da pereira. Esse mesmo comportamento foi também relatado por Zhao et al. (2015) que avaliando o déficit hídrico em pereira nas suas fases fenológicas, observaram que durante o estádio de crescimento do fruto houve redução das taxas de condutância e transpiração. Além disso, em trabalhos realizados com a macieira irrigada na região semiárida do Brasil, observou-se que a restrição hídrica também reduziu as taxas de fotossíntese, transpiração e condutância estomática (OLIVEIRA et al., 2017). Em estudos com a cultura da pereira em região de clima temperado, nos tratamentos submetidos ao déficit hídrico (20\% da ETc), observou-se também que os valores de condutância estomática foram inferiores às parcelas que receberam 100\% da ETc (MORANDI et al., 2014).

Do mesmo modo, a restrição hídrica pode acarretar no aumento da temperatura foliar limitando a fotossíntese (OLIVEIRA et al, 2017). O processo fotossintético pode ser prejudicado quando há aumento da temperatura do ambiente, ocasionado pela redução da umidade relativa do ar e esses fatores podem resultar no fechamento estomático havendo diminuição das trocas gasosas da cultura (SILVA et al., 2013).

Entretanto, pode-se notar também que o excesso de água provocou redução nas taxas de condutância estomática (Figura 1A), transpiração (Figura 1B), fotossíntese (Figura 1C) e aumento na temperatura (Figura 1D).

De uma maneira geral, as médias da condutância estomáticas encontradas nesse trabalho são superiores aos obtidos por Zhao et al (2015), em que os valores da condutância estomática encontradas pelos mesmos foram inferiores a $0,18 \mathrm{~mol} \mathrm{de} \mathrm{H}_{2} \mathrm{O} \mathrm{m}^{-2} \cdot \mathrm{s}^{-1}$ e as taxas fotossintéticas não ultrapassaram $14,00 \mu \mathrm{mol} \cdot \mathrm{m}^{-2} \cdot \mathrm{s}^{-1} \mathrm{de} \mathrm{CO}_{2}$, em zona semiárida da China.

A fisiologia da pereira depende de características bióticas e abióticas, como o cultivar, a espécie e o clima, respectivamente (ZARAFSHAR et al., 2014). Esses mesmo autores, perceberam que cultivares de Pyrus oriundos de regiões semiáridas iraniana apresentaram altas taxas na capacidade de recuperação do déficit hídrico, como aumento nos valores de fotossíntese, transpiração e condutância estomática.

Entretanto, esse comportamento não corrobora com os resultados encontrados nesse estudo, tendo em vista que não houve interação significativa entre os fatores analisados, como o tipo de sistema de irrigação e a cultivar empregada. Esse cenário, pode estar associado com as características fisiológicas semelhantes entre as variedades, principalmente, pelo fato das cultivares estudados possuírem o mesmo genótipo, tendo em vista que a pereira 'Triunfo' é um híbrido obtido a partir do cruzamento entre a 'Hood' e a 'Packham's triumph'. 


\section{CONCLUSÕES}

As lâminas de irrigação interferiram nos processos fisiológicos da cultura da pereira, sendo os melhores valores proporcionados pelas lâminas próximo de $100 \%$ da ETc.

Não houve interação entre os sistemas de irrigação e as variedades de pereira estudadas quanto às características de fotossíntese, transpiração, condutância estomática e temperatura foliar.

\section{REFERÊNCIAS BIBLIOGRÁFICAS}

ALLEN, R; PEREIRAS, L. S.; RAEKS, D.; SMITH, M. 2006. Evapotranspiración del cultivo, Guías para la determinación de los requerimientos de agua de los cultivos, Estudio FAO Riego y Drenaje, No. 56, Roma, Italia, 298p.

ANDRADE, C. L. T.; BORGES JÚNIOR, J. C. F.; COUTO, L. Características físico hídricas e dinâmica de água no solo. In: ALBUQUERQUE, P. E. P.; DURÃES, F. O. M. Uso e manejo de irrigação. Brasília, DF: Embrapa Informação Tecnológica, 2008. p. 403-419.

BETTIOL NETO, J. E.; CHAGAS E. A.; SANCHES, J.; R; PIO, R; ANTONIALI, S. CIA, $P$. Production and postharvest quality of pear tree cultivars in subtropical conditions at eastern of São Paulo state, Brazil. Ciência Rural, v.44, n.10, p. 1740-1746, 2014.

BIANCHI, C. A. M; BERGONCI, J. I.; BERGAMASCHI, H.; DALMAGO, G. A.; HECKLER, B. M. M.; COMIRAN, F. Condutância da folha em milho cultivado em plantio direto e convencional em diferentes disponibilidades hídricas. Revista Ciência Rural, v. 37, n. 2, 2007.

CHAVES, M. M.; FLEXAS, J.; PINHEIRO, C. Photosynthesis under drought and salt stress: regulation mechanisms from whole plant to cell. Annals of Botany, v. 103, p. 551- 560, 2009.

COELHO E. F.; OLIVEIRA, F. C.; ARAUJO, E. C. E.; VASCONCELOS, L. F. L.; LIMA, D. M. Distribuição do sistema radicular da mangueira sob irrigação localizada em solo arenoso de Tabuleiros Costeiros. Revista Brasileira de Fruticultura, v. 23, p. 250-256, 2001.

FLEXAS, J; BOTA, J.; LORETO, F.; CORNIC, G.; SHARKEY, T. D. Difusive and metabolic limitations on photosynthesis under dhought and salinity in C3 plants. Plant Biology, v. 6, p. 1-11, 2004.

FRIZZONE, J. A.; FREITAS, P. S. L.; REZENDE, R.; FARIA, M. A. Microirrigação: Gotejamento e Microaspersão. 1. ed. Maringá: Eduem - Editora da Universidade Estadual de Maringá, 2012. v.1. 356p.

LOPES, I.; GUIMARÃES, M. J. M.; MELO, J. M. M.; RAMOS, C. M. C. Balanço hídrico em função de regimes pluviométricos na região de Petrolina-PE. Revista Irriga, 22, n.3, p.443-457, 2017. 
LOPES, P. R. C.; OLIVEIRA, I. V. M.; SILVA-MATOS, R. R. S.; CAVALCANTE, I. H. L. Caracterização fenológica de pereiras 'Housui' e 'Kousui' cultivadas sob clima semiárido no Nordeste do Brasil. Revista Brasileira de Fruticultura, v. 35, n. 2, p. 105-110, 2013.

MORANDI, B; LOSCIALE, P.; MANFRINI, L.; ZIBORDI, M.; ANCONELLI, S.; GALLI, F.; PIERPAOLI, E.; GRAPPADELLIA, L. C. Increasing water stress negatively affects pear fruit growth by reducing first its xylem and then its phloem inflow. Journal of Plant Physiology, v.171, p.1500-1509, 2014.

NEMESKÉRI, E.; KOVÁCS-NAGY, E.; NYÉKI, J.; SÁRDI, E. Responses of apple tree cultivars to drought: carbohydrate composition in the leaves. Turkish Journal of Agriculture and Forestry, v.39, p.949-957, 2015.

OLIVEIRA, A. F.; MEDEIROS, J. F. DE; LIMA, C. J. G. S.; DUTRA, I.; OLIVEIRA, M. K. T. Eficiência agronômica da fertirrigação nitrogenada e potássica na cultura do meloeiro nas condições do Semiárido nordestino. Revista Caatinga, v.21, p.5-11, 2008.

OLIVEIRA, A. K. M.; GUALTIERI, S. C. J. Trocas gasosas e grau de tolerância ao estresse hídrico induzido em plantas jovens de Tabebuia aurea (Paratudo) submetidas a alagamento. Revista Ciência Florestal, v. 27, n. 1, p. 181-191, 2017.

OLIVEIRA, C. P. M.; SIMÕES, W. L.; SILVA, J. A. B.; LOPES, P. R. C.; ARAUJO, E. F. J.; CAVALCANTE, B. L. S. Flowering, fruiting and physiology of apple tree under different irrigation levels in the Brazilian semiarid region. Comunicata Scientiae, v. 8, p. 99-108, 2017

PADILHA, N. S; SILVA, C. J.; PEREIRA, S. B.; SILVA, J. A. N.; HEID, D. M.; BOTTEGA, S. P.; SCALON, S. P. Q. Crescimento inicial do pinhão-manso submetido a diferentes regimes hídricos em Latossolo Vermelho distrófico. Ciência Florestal, v. 26, n. 2, p. 513-521, 2016.

RODRIGUES, E. V.; SILVA, K. J. D.; ROCHA, M. M.; BASTOS, E. A.; SANTOS, A. Tolerance of $\mathrm{f}_{2}$ populations of cowpea to water deficit. Revista Caatinga, v. 31, n. 1, p. 48$55,2018$.

SARAIVA, K. R.; BEZERRA, F. M. L.; SOUZA, F.; CAMBOIM NETO, L. F. Aplicação do "ISAREG" no manejo da irrigação na cultura da melancia no Baixo Acaraú, Ceará. Revista Ciência Agronômica, v. 44, n. 1, p. 53-60, 2013.

SILVA, A. R. A.; BEZERRA, F, M, L.; LACERDA, C. F.; PEREIRA FILHO, J. V.; FREITAS, C. A. S. Trocas gasosas em plantas de girassol submetidas à deficiência hídrica em diferentes estádios fenológicos. Revista Ciência Agronômica, v.44, n.1, p.86-93, 2013.

SILVA, Á. F. S.; LIMA, C. A.; QUEIROZ, J. J. F.; JÁCOME, P. R. L. A.; JÁCOME JÚNIOR, A. T. Análise bacteriológica das águas de irrigação de horticulturas/Bacteriological analysis of horticultural irrigation water. Revista Ambiente \& Água, v.11, n.2, p.428-439, 2016.

SIMÕES, W. L.; FERREIRA, P. P. B.; MOUCO, M. A. C.; LIMA, M. A. C.; GUIMARÃES, 
M. J. M.; SILVA, J. A. B. Produção e respostas fisiológicas da mangueira cv. Keitt sob diferentes sistemas de irrigação no Submédio do São Francisco. Revista Irriga, v. 23, n.1, p.34-43, 2018.

TAIZ, L.; ZEIGER, E. Fisiologia vegetal. 6. ed. Porto Alegre: Artmed, 2017. 858p.

WREGE, M. S.; HERTER, F. G.; FRITZSONS, E. Regiões com similaridade de horas de frio no outono-inverno no sul do Brasil. Revista Brasileira de Climatologia, v. 18, p. 108-121, 2016.

ZARAFSHAR, M.; AKBARINIA, M.; ASKARI, H.; HOSSEINI, S. M.; RAHAIE, M.; STRUVE, D.; STRIKER, G. G. Morphological, physiological and biochemical responses to soil water deficit in seedlings of three populations of wild pear tree (Pyrus boisseriana). Biotechnology, Agronomy and Society and Environment, v. 18, n.3, p.353-366, 2014.

ZHAO, Z.; WANG, W.; WU, Y.; XU, M.; HUANG, X.; MA, Y.; REN, D. Leaf physiological responses of mature pear trees to regulated deficit irrigation in field conditions under desert climate. Scientia Horticulturae, v.187, p. 122-130, 2015. 